\title{
Are We Moving Towards a New Era in Minimally Invasive Thoracic Surgery?
}

\author{
Jalal Assouad • Dominique Grunenwald
}

Received: 11 December 2009 /Accepted: 15 June 2010 / Published online: 29 June 2010

(C) 2010 The Society for Surgery of the Alimentary Tract

We read with big interest the paper by Swanstrom et al. ${ }^{1}$ in which authors described the use of a flexible endoscope in oesophageal surgery through a cervical incision.

Swanstrom et al. demonstrated here the feasibility of oesophageal mobilisation and dissection in a para-oesophageal plane using a flexible endoscope through a small cervical incision. Authors emphasised the inescapable help provided by positive pressure $\mathrm{CO}_{2}$ mediastinoscopy in the creation and dissection of tissue planes in the mediastinum. They also mentioned a severe cardiopulmonary derangement in one animal due to mediastinum high pressure.

The para-oesophageal plan is located in the same anatomical space than the para-tracheal plane which is bordered by the mediastinal pleura. The creation of a communication between the para-tracheal space and the pleural cavity through the mediastinal pleura (pleurotomy) offers a good access to pleural cavities through a cervical incision. ${ }^{2,3}$

Our questions to doctor Swanstrom are the following: before the step of oesophageal dissection using gas inflation, do you think that the creation of a communication between the latero-tracheal space and the pleura using classical mediastinoscopic instruments, which did not necessitate any gas inflation, could offer a better control of the mediastinal inflation pressure during the following oesophageal dissection? And do you think that this communication helped by a simple intercostal needle to evacuate supplementary pressure could diminish the cardiopulmonary derangement due to mediastinal inflation?

The creation of a communication between the mediastinum and pleural cavity through a cervical incision has already been described using classical thoracoscopic tools. ${ }^{2,3}$ Unfortunately, the rigidity of classical instruments did not allow a large exploration of the pleural cavity.

Using flexible endoscope property through validated and classical cervical access (mediastinoscopy) seems to be more adapted for thoracic specificities and could avoid major mediastinal complications than in N.O.T.E.S. approaches. In addition, it could afford large applications in the pleural cavity through single cervical incision.

More experimental studies are needed to assess the role of flexible endoscope in the exploration of the mediastinum and pleura through a cervical incision using a flexible endoscope.

\section{References}

1. Swanstrom, L L, Dunst CM, Spaun, GO (2010) Future applications of flexible endoscopy in esophageal surgery. J Gastroint Surg 14:127-32

2. Chamberlain MH, Fareed K, Nakas A, Martin-Ucar AE, Waller DA (2008) Video-assisted cervical thoracoscopy: a novel approach for diagnosis, staging and pleurodesis of malignant pleural mesothelioma. Eur J Cardiovasc Surg 34:200-3

3. Fowkes L, Lau KK, Shah N, Black E. A cervical approach to investigating pleural disease. Ann Thorac Surg 88:315-7.

J. Assouad ( $\square)$

Department of Thoracic Surgery, Hôpital Tenon, APHP,

Paris, France

e-mail: jalal.assouad@tnn.aphp.fr

D. Grunenwald

Hôpital Tenon, APHP,

Paris, France 